\title{
Antioxidant properties of the red alga Asparagopsis taxiformis collected on the North West Algerian coast
}

\author{
ZOHEIR MELLOUK ${ }^{1}$, ILHEM BENAMMAR ${ }^{2}$, DJAMIL KROUF ${ }^{3}$, \\ MAKHLOUF GOUDJIL ${ }^{4}$, MERIEM OKBI ${ }^{4}$ and WILLY MALAISSE ${ }^{5}$
}

\begin{abstract}
Laboratories of ${ }^{1}$ Physiology of Nutrition and Food Safety, ${ }^{2}$ Development and Differentiation Biology and ${ }^{3}$ Clinical and Metabolic Nutrition; ${ }^{4}$ Department of Biology, Faculty of Natural and Life Sciences, University of Oran 1 Ahmed Ben Bella, 31000 Oran, Algeria; ${ }^{5}$ Department of Biochemistry, Université Libre de Bruxelles, B-1070 Brussels, Belgium
\end{abstract}

Received December 15, 2016; Accepted February 1, 2017

DOI: $10.3892 / \mathrm{etm} .2017 .4413$

\begin{abstract}
The aim of the present study was to evaluate the total phenolic and lipid content, fatty acids profiles and in vitro antioxidant activities of aqueous and solvent extracts of the red seaweed Asparagopsis taxiformis, through six different investigations. The present study demonstrated that phenol contents (mg gallic acid/g dry weight) were highest in the aqueous and methanolic extracts, followed by the ethanolic, hydroethanolic and hydromethanolic extracts. The lowest phenol contents were identified in the three remaining extracts: Butanolic, petroleum ether and acetone extracts. Furthermore, the total lipid content of the algae powder amounted to $2.85 \%$ of dry weight. The fatty acid methyl ester profiles analysed by gas-liquid chromatography represented indicated that fatty acids comprised $91.0 \pm 0.3 \%$ of total algae lipids. The saturated to unsaturated fatty acid contents amounted to $23.2 \pm 0.1$ and $67.9 \pm 0.4 \%$ respectively. $\mathrm{C} 13: 0$ (tridecanoate), $\mathrm{C} 15: 0$ (pentadecanoate) and C17:0 (heptadecanoate) represented $47.4 \%$ of the total saturated fatty acids. Notably, the two most abundant unsaturated fatty acids, C15:1 (pentadecenoate) and C18:2 (octadecadienoate) represented 13.4 and $11.4 \%$ respectively, of the total unsaturated fatty acid content. Furthermore, the results of the antioxidant screening performed at $1.0 \mathrm{mg} / \mathrm{ml}$, revealed that aqueous and methanolic extracts exhibited higher inhibition against superoxide and nitric oxide radicals and excellent radical scavenging activity [with half maximal inhibitory concentration $\left(\mathrm{IC}_{50}\right.$ ) values 5.1 and $15.0 \mu \mathrm{g} / \mathrm{ml}$, respectively], demonstrating improved antioxidant behavior when compared with standard ascorbic acid (which has an $\mathrm{IC}_{50}$ value of $3.7 \mu \mathrm{g} / \mathrm{ml}$ ). Scavenging activity of the aqueous and
\end{abstract}

Correspondence to: Professor Willy Malaisse, Department of Biochemistry, Université Libre de Bruxelles, 808 Route de Lennik, B-1070 Brussels, Belgium

E-mail:malaisse@ulb.ac.be

Key words: Asparagopsis taxiformis, total phenolics, 1,1-diphenyl2-picryl-hydrazyl radical, ferric ion reducing antioxidant parameter, nitric oxide scavenging activity, linoleic acid peroxidation methanolic extracts exhibited a strong peroxidation inhibition against linoleic acid emulsion system at a concentration of $300 \mu \mathrm{g} / \mathrm{ml}$ in comparison to the butylated hydroxyltoluene. Although all the studied extracts exhibited ferric reducing power, the aqueous and methanolic extracts had greater hydrogen donating ability. By contrast, hydromethanolic, ethanolic, hydroethanolic, butanolic, acetone and petroleum ether extracts exhibited weak antioxidant behavior. The antioxidant activity of potent seaweed species identified in the current study means that as well as being used as a functional food, they may be developed as novel pharmaceutical compounds and may be used as anti-ageing agents.

\section{Introduction}

The Algerian Mediterranean coast is an exclusive habitat for a number of algae species and investigating these species may lead to the identification of novel therapeutic agents to treat human diseases such as cancer, obesity, diabetes, inflammation, allergies and numerous bacterial and fungal infections (1-5).

Numerous studies have attempted to identify and characterize sea algae (6-8). However, successfully evaluating their biological activity has proven difficult, mainly due to the availability of a wide variety of algal species, and the environment undergoing rapid fluctuations in light intensity, temperature, osmotic stress, salinity, desiccation and pathogen contamination. Among the diverse varieties of algae, red algae form a heterogeneous group according to their chemical composition (9). Asparagopsis taxiformis is a species of red algae that represents the most abundant biomass in the Algerian coast.

The complex habitats in which algae are found, in addition to the extreme environmental conditions (changes of salinity, temperature, nutrients, ultraviolet radiation) they are exposed to, stimulate rapid adaptation. Algae adapt to these conditions by producing a variety of bioactive compounds during their growth cycle, including essential amino acids derived from high quality proteins, alimentary fibers and minerals $(10,11)$, as well as other chemical compounds possessing diverse pertinent biological activity (12-14), which cannot be found in other organisms (15).

These photosynthetic organisms are exposed to a combination of high oxygen concentrations and sunlight, which induce 
the formation of free radicals and other reactive oxygen species. The absence of structural damage in algae implies that these organisms are able to generate natural antioxidants including polyphenols, vitamins and polyunsaturated fatty acids (16).

The antioxidant activity of natural bioactive compounds prepared from these algae has generated interest amongst researchers, due to the interest of the pharmaceutical industry in developing novel molecules with therapeutic functions that may prevent or treat a number of diseases (cancer, chronic inflammation, atherosclerosis, cardiovascular troubles, diabetes and obesity), and attenuate the process of aging (17-20) which is linked to oxidative stress. Such novel molecules may have health benefits, due to their high nutritional value and antioxidant power $(21,22)$.

Oxidant stress is the cause of almost all cases of morbidity today. It may cause toxicity, acidity, alteration and degeneration involved in the majority of chronic diseases currently diagnosed in individuals, including atherosclerosis, cancer, diabetes, arterial hypertension and hypercholesterolemia $(23,24)$. Oxidant stress is a phenomenon affecting individuals of all ages and social conditions throughout the world. However, older individuals are, in this respect, more vulnerable due to their weakening antioxidant profile. Indeed, it has been determined that the occurrence of oxidative stress is inversely proportional to the antioxidant capacity of the organism (23). Therefore, the primary aim of current investigations aiming to attenuate oxidative stress is to identify easily accessible natural sources of antioxidant micronutrients that are able to oppose the effects of free radicals. Numerous treatments for common aliments that utilize antioxidant micronutrients have emerged in several medical fields. Such treatments are often favoured over instructing patients to follow a healthy, balanced diet enriched in natural sources of antioxidants, despite their high cost and on occasion, restricted availability (23).

The present study aimed to evaluate the antioxidant potential of different extracts of Asparagopsis taxiformis using six standard biochemical tests: Phenolic compounds titration, DPPH reduction, ferric ion reducing antioxidant method, nitric oxide radical scavenging assay, inhibition of superoxide radical and lipidic peroxidation inhibition.

\section{Materials and methods}

Biological material. Red alga Asparagopsis toxiformis (2 kg) was collected on the coast of Oran in northwest Algeria at a depth of 3-5 m, close to the rocks of Bousfer beach (Coralès) between September and November 2015. The algae were rinsed with sea water and then tap water, and dried in the dark at ambient temperature for three days. Powder material was obtained by crushing with an electric grinder and sieving, prior to being stored in the dark at an ambient temperature in hermetically closed glass bottles.

Procedure for the preparation of powder extract. Various extracts were prepared from $5 \mathrm{~g}$ algae powder placed in $100 \mathrm{ml}$ of eight different solvents and allowed to macerate for $48 \mathrm{~h}$ under constant agitation at ambient temperature. The solvents consisted of distilled water (aqueous extract), a 31.8/68.2 (v/v) methanol/water mixture (hydro-methanolic extract), a 35.0/65.0 (v/v) ethanol/water mixture (ethanolic extract), methanol at $95 \%(\mathrm{v} / \mathrm{v})$ (methanolic extract), ethanol at 95\% (v/v) (ethanolic extract), butanolic at $90 \%$ (v/v) (butanolic extract), Petroleum ether at $95 \%$ (v/v) (Petroleum ether extract) and acetone at $95 \%(\mathrm{v} / \mathrm{v})$ (acetone extract).

Following $48 \mathrm{~h}$ maceration with constant stirring at room temperature, extracts were filtered through a $20 \mu \mathrm{m}$ Whatman paper filter and the collected liquid phase was placed in duly pre-weighed bottles with a polished neck. Evaporation was conducted at $40^{\circ} \mathrm{C}$ for $1 \mathrm{~h}$ using an R-300 Rotavapor ${ }^{\circledR}$ (Buchi Labortechnik AG, Flawil, Switzerland) and subsequently, bottles containing dry matter were kept for 1 day in a drying store at $40^{\circ} \mathrm{C}$ and weighed again. This allowed an estimate of extraction procedure efficiency, following subtraction of the initial bottle weight.

Titration of total phenolic compounds. The total phenol content of Asparagopsis taxiformis extracts was assessed using the yellow Folin-Ciocalteu reagent (Sigma-Aldrich, Merck KGaA, Darmstadt, Germany), formed of phosphotungstic acid $\left(\mathrm{H}_{3} \mathrm{PW}_{12} \mathrm{O}_{40}\right)$ and phosphomolybdic acid $\left(\mathrm{H}_{3} \mathrm{PMo}_{12} \mathrm{O}_{40}\right)$. This reagent generates blue tungsten and molybdenum oxides when reduced during phenol oxidation (25).

Then, $50 \mu \mathrm{l}$ algae extract was mixed with $2.5 \mu 1$ distilled water and $250 \mu \mathrm{l}$ diluted (1/10) Folin-Ciocalteu reagent. Following agitation and 3 min incubation in the dark at room temperature, $1.0 \mathrm{ml} \mathrm{Na}_{2} \mathrm{CO}_{3}(20 \mathrm{~g} / 100 \mathrm{ml})$ was added, followed by $30 \mathrm{~min}$ incubation under the same experimental conditions. The absorbance was measured using a spectrophotometer (Jenway 7300, Cole-Parmer Europe, Stone, UK) at $760 \mathrm{~nm}$ vs. blank (methanol).

In parallel, a standard reference curve was established under the same experimental conditions using gallic acid as a positive control. The results were expressed as $\mathrm{mg}$ gallic acid equivalent per $g$ dry matter. In the standard curve, absorbance was almost proportional to the amount of gallic acid (200, $400,600,800$ and 1,000 $\mu \mathrm{g} /$ tube) with an overall mean optical density ( \pm standard error of the mean) of $21.3 \pm 1.4$ arbitrary units per mg gallic acid $(n=5)$.

Extraction and assay of total lipids. The extraction of lipids from the Asparagopsis taxiformis samples was achieved by the soxhelet method (26). A wherry containing $100 \mathrm{~g}$ fine ground algae powder was placed in the upper compartment of the extraction apparatus (Thermo Fisher Scientific, Inc., Waltham, MA, USA) that was connected to a cooling circuit. A total of $600 \mathrm{ml}$ chloroform/methanol mixture was then added according to the protocol recommended by Bligh and Dyer (27). The bottom of the apparatus consisted of bottles (previously accurately weighed) placed on a heating plate at $45^{\circ} \mathrm{C}$ with integrated magnetic agitation. The extraction lasted for $\sim 8 \mathrm{~h}$ ( 12 cycles). The chloroform/methanol mixture was then evaporated using a rotating vapor device (R-300 Rotavapor ${ }^{\circledR}$ ). The resulting residue was dried overnight on phosphoric anhydride (Biochem Chemopharma, Cosne-Cours-sur-Loire, France) in a vacuum dessicator (Thermo Fisher Scientific, Inc.).

Total lipid content of the samples was judged by the difference in weight of each bottle prior to this procedure and at its end, and expressed as a percentage of initial dry matter. Fatty acids were converted to their methylic ester according to a protocol 
previously described by Christie (28). The esterification of the samples was conducted in absolute methanol containing $1 \%$ sulfuric acid, and hexane was used to extract and separate the different phases. The hexane phase was rinsed with water and potassium bicarbonate, and then dried with anhydrous sodium sulfate. The solvent was eventually evaporated using a rotating vapor device (RS 3000-V; J.P. Selecta s.a, Abrera, Spain). The methylic esters were analyzed by gas-liquid chromatography system (29) (Shimadzu Corporation, Kyoto, Japan), equipped with a flame ionization detector and a type Hp-5 fused-silica capillary column (30 m length, $0.25 \mathrm{~mm}$ internal diameter, $0.25 \mu \mathrm{m}$ film thickness; Sigma-Aldrich; Merck KGaA). The mobile gas phase consisted of nitrogen with a constant delivery of $5 \mathrm{~mm} / \mathrm{min}$. The identification and quantification of the fatty acid methylic esters (FAME) was achieved by comparing their retention time with a standard 37 component FAME mixture (cat. no. 18919-1Amp; Sigma-Aldrich; Merck KGaA) Results were expressed as a percentage of total fatty acids.

1,1-diphenyl-2-picrylhydrazyl (DPPH) scavenging assay to assess antioxidant power. The DPPH radical possesses an unpaired electron on an atom of a nitrogen bridge. Due to this dislocalization, the radical molecules do not form a dimer and DPPH remains in its monomeric form, relatively stable at $25^{\circ} \mathrm{C}$. This dislocalization provokes the appearance of a blue colour characteristic of DPPH solution (30). The addition of the DPPH radical to an ethanolic/methanolic or aqueous solution containing a compound with antioxidant potential able to yield protons $\left(\mathrm{SH}^{-}, \mathrm{NH}^{-}\right.$or $\left.\mathrm{OH}^{-}\right)$provokes the neutralization of the DPPH free radical towards its reduced form (DPPH-H). The latter reaction is accompanied by a decrease in the violet colour characteristic of the free form of DPPH and the appearance of a yellow colour. Ascorbic acid (Sigma-Aldrich; Merck $\mathrm{KGaA}$ ) was used as the standard and methanol was the blank. The discoloration, measurable with a Jenway 7300 spectrophotometer at $515-518 \mathrm{~nm}$ was proportional to the capacity of the antioxidants present in the medium. The half maximal inhibitory concentration $\left(\mathrm{IC}_{50}\right)$ of each extract was judged by referring to a curve relating the logarithm of the inhibition percentage to the concentration of the tested extract. The radical scavenger activity (RSA), expressed as a percentage, refers to the ratio between the absorbance of the tested samples following $30 \mathrm{~min}$ incubation at room temperature and the optical density of the control containing DPPH in methanol.

Ferric ion reducing antioxidant parameter to assess antioxidant power. The Ferric ion Reducing Antioxidant Parameter (FRAP) method, designed by Benzie and Strain (31), measures the capacity of tested extracts to reduce iron. At a low $\mathrm{pH}$, when the ferric-tripyridyltriazin ( $\mathrm{Fe}^{\mathrm{III}}-\mathrm{TPTZ}$ ) complex is reduced to its $\mathrm{Fe}^{\mathrm{II}}$ form, an intense blue colour develops in the reaction medium, with maximal absorption at $593 \mathrm{~nm}$. The development of the blue colour therefore occurs in the presence of reducing, i.e. antioxidant, agents. This FRAP method is based on the use of the $\mathrm{Fe}^{\mathrm{III}}$ in excess, the limiting factor for the formation of the $\mathrm{Fe}^{\mathrm{II}}-\mathrm{TPTZ}$ complex being the reducing power of the sample under consideration.

The reagents included an acetate buffer $\left(\mathrm{C}_{2} \mathrm{H}_{3} \mathrm{NaO}_{2} \cdot 3 \mathrm{H}_{2} \mathrm{O}\right.$; $300 \mathrm{mM})$ at pH 3.6 in $16 \mathrm{ml}$ acetic acid $\left(\mathrm{C}_{2} \mathrm{H}_{4} \mathrm{O}_{2}\right)$ per $\mathrm{L}$ of buffer, 2,4,6-Tripyridyl-s-Triazine (TPTZ) $10 \mathrm{mM}$ in $40 \mathrm{mM}$
$\mathrm{HCl}$ and $20 \mathrm{mM}$ iron chloride $\left(\mathrm{FeCl}_{3} \cdot 6 \mathrm{H}_{2} \mathrm{O}\right)$, all purchased form Merck KGaA. The FRAP reagent was freshly prepared by mixing $25 \mathrm{ml}$ acetate buffer with $2.5 \mathrm{ml}$ TPTZ solution and $2.5 \mathrm{ml} \mathrm{FeCl}{ }_{3} \cdot 6 \mathrm{H}_{2} \mathrm{O}$ solution. To $2 \mathrm{ml}$ FRAP reagent, $0.5 \mathrm{ml}$ of either ascorbic acid standard or the tested samples were added.

The optical density of each sample was measured at a wavelength of $593 \mathrm{~nm}$ immediately following incubation for $30 \mathrm{~min}$ at $50^{\circ} \mathrm{C}$, and a further 4 min later. The absorbance change over this period with the standards or tested samples is used to express results as $\mathrm{mM} \mathrm{Fe}^{\mathrm{II}}$ per mg dry matter.

The min 4-min 0 difference in optical density of $\mathrm{FeSO}_{4} .7 \mathrm{H}_{2} \mathrm{O}$ standards yielded results in the $0.1-1.0 \mathrm{mM}$ range, proportional to the latter concentration. Thus, at six different concentrations $(0.1,0.2,0.4,0.6,0.8$ and $1.0 \mathrm{mM})$ of ferric chloride standard solution, the mean readings, each derived from triplicate measurements averaged, were expressed relative to the reagent concentration, $33.95 \pm 1.33 .10^{-3}$ (mean \pm standard error of the mean; $n=6$ ).

Nitric oxide radical scavenging assay to assess antioxidant power. Nitric oxide, generated from sodium nitroprusside, interacts with oxygen to produce nitrite ions, which may be identified using Griess reagent (32), containing 1\% sulfanilamide solution in $5 \%$ phosphoric acid and $0.1 \%$ naphthylethylenediamine dihycrochloride in distilled water. The principle of this procedure is to measure the capacity of extracts to scavenge nitric oxide, which leads to the reduced production of nitrite ions. This is detected by formation of a red-pink colour upon treatment of a nitrite ion-containing sample with the Griess reagent (33).

For this purpose, $0.5 \mathrm{ml}$ each algae extract $(1.0 \mathrm{mg} / \mathrm{ml})$ was added to $0.5 \mathrm{ml}$ phosphate buffer $(25 \mathrm{mM}, \mathrm{pH} 7.4)$ and $2.0 \mathrm{ml}$ sodium nitroprusside $(5 \mathrm{mM})$. Following $2 \mathrm{~h}$ incubation at $30^{\circ} \mathrm{C}$, the samples were mixed with $0.25 \mathrm{ml}$ trichloroacetic acid $(25 \%)$ and centrifuged at $3,000 \times \mathrm{g}$ for $20 \mathrm{~min}$ at $4^{\circ} \mathrm{C}$. Thereafter, $0.25 \mathrm{ml}$ supernatant was mixed with $0.25 \mathrm{mM}$ Griess reagent and further incubated for $30 \mathrm{~min}$ in the dark at an ambient temperature.

Ascorbic acid was used as a reference and was subjected to the same treatment conditions as the other samples. The percentage inhibition of the nitric oxide radical was taken as the difference in optical density between the control and the sample. This difference is expressed as relative to the optical density of the control.

Inhibition of superoxide radical. The method used to evaluate the capacity of Asparagopsis taxiformis extracts to bind the superoxide $\mathrm{O}_{2}$ anion, which was generated in vitro by the hypoxanthine/xanthine oxidase, was based on the conversion of yellow coloured nitro-blue tetrazolium $\left(\mathrm{NBT}^{2+}\right)$ to purple coloured formazan blue. Absorbance was measured at $560 \mathrm{~nm}$ using Jenway 7300 spectrophotometer. Any antioxidant compound able to bind the superoxide anion impedes the generation of formazan blue. The percentage of $\mathrm{NBT}^{2+}$ conversion to formazan blue was estimated by reference to a reagent medium deprived of any antioxidant compound (34).

This procedure was conducted in a phosphate buffer (50 mM, pH 7.5) containing EDTA $(0.05 \mathrm{mM})$, hypoxanthine $(0.2 \mathrm{mM}), 63 \mu \mathrm{l}$ nitro-blue tetrazolium $(1.0 \mathrm{mM}), 63 \mu \mathrm{l}$ of either distilled water (control) or an alga extract $(1 \mathrm{mg} / \mathrm{ml})$ and $63 \mu \mathrm{l}$ 
xanthine oxidase $(1.2 \mathrm{U} / \mu \mathrm{l})$, the latter oxidase being added at the last moment. The reaction mixture was then incubated at $25^{\circ} \mathrm{C}$ for $5 \mathrm{~min}$.

The extent of NBT reduction was determined by measuring the spectrophotometric absorbance at $560 \mathrm{~nm}$ (34). The results were expressed as a percentage inhibition of NBT reduction compared with the distilled water control.

Inhibition of linoleic acid peroxidation. Antioxidant activity of the algae extract was judged by the inhibition of linoleic acid peroxidation using the iron thiocyanate method proposed by Bidie et al (35). A linoleic acid emulsion was first prepared by mixing $28 \mathrm{mg}$ linoleic acid (Diet Form, Clermont-Ferrand, France), $28 \mathrm{mg}$ Tween 20 and $10 \mathrm{ml}$ phosphate buffer $(0.04 \mathrm{M}$, $\mathrm{pH}$ 7.0). The reaction milieu consisted of $0.6 \mathrm{ml}$ butylhydroxytoluene (BHT) antioxidant standard $(50 \mu \mathrm{g} / \mathrm{ml})$ or alga extract and $0.6 \mathrm{ml}$ linoleic acid emulsion. A negative control contained $0.6 \mathrm{ml}$ of phosphate buffer $(0.04 \mathrm{M}, \mathrm{pH} 7.0)$ and $0.6 \mathrm{ml}$ linoleic acid emulsion. Following agitation, the mixture was incubated at $25^{\circ} \mathrm{C}$ for $15 \mathrm{~min}$ in the dark.

The $\mathrm{IC}_{50}$ of each compound was determined using the curve relating the logarithmic value for the percentage inhibition to the concentration of the tested compound. The percentage inhibition of lipid peroxidation was estimated from the difference between the absorbance of the tested compound minus that of the control, the latter difference being then divided by the absorbance of the control.

Statistical analysis. All in vitro experimental results are presented as mean \pm standard error of the mean from three parallel replicates and data were evaluated using Student's t-test. The correlation coefficient was calculated by simple linear correlation analysis (36). $\mathrm{P}<0.05$ was determined to represent a significant difference. Results were processed using GraphPad PRISM v5.0 (GraphPad Software, Inc., La Jolla, CA, USA).

\section{Results}

Efficiency of extraction. The yield of the extraction procedure, expressed as the weight percentage of collected dry matter relative to the initial algae powder amounted to $24.0 \%$ for the aqueous extract, $21.3 \%$ for the methanolic extract, $18.1 \%$ for the ethanolic extract, $15.9 \%$ for the hydromethanolic extract, $12.6 \%$ for the butanolic extract, $12.1 \%$ for the hydroethanolic extract, $8.8 \%$ for the acetone extract and $4.8 \%$ for the petroleum ether extract. Therefore, the extraction procedure of the aqueous extract was judged to be the most efficient.

Total polyphenic content of algae extracts. The total polyphenol content of the powdered extract, expressed as mg gallic acid equivalent per $\mathrm{g}$ dry matter averaged, was $385 \mathrm{~g}$ for the aqueous extract, $242 \mathrm{~g}$ for the methanolic extract, $216 \mathrm{~g}$ for the ethanolic extract, $189 \mathrm{~g}$ for the hydroethanolic extract, $127 \mathrm{~g}$ for the hydromethanolic extract, $115 \mathrm{~g}$ for the butanolic extract, $83 \mathrm{~g}$ for the petroleum ether extract and $69 \mathrm{~g}$ for the acetone extract.

Lipid content of the alga powder. The lipid content of the alga powder amounted to $2.85 \pm 0.08 \%$ of dry matter. Table I provides information on the percentages of both saturated and unsaturated fatty acids relative to total lipid content. The total content of such fatty acids represented $91.0 \pm 0.3 \%$ of the algae lipids.

The fractional contribution of saturated and unsaturated fatty acids amounted to $23.2 \pm 0.1$ and $67.9 \pm 0.4 \%$ respectively, yielding a saturated/unsaturated mean ratio of 0.34 . C13:0 (tridecanoate), C15:0 (pentadecanoate) and C17:0 (heptadecanoate) made up the highest proportion of the saturated fatty acids. These three saturated fatty acids accounted for $47.4 \%$ of total saturated fatty acids and the individual contribution of C15:0 to the total amount of saturated fatty acids was $28.1 \%$. Similarly, the unsaturated fatty acids, C22:6 (docosahexaenoate) accounted for $48.9 \%$ of the total amount of such unsaturated fatty acids. C15:1 (pentadecenoate) and C18:2 (octadecadienoate), the other two most abundant unsaturated fatty acids, represented 3.4 and $11.4 \%$ of the total amount of unsaturated fatty acids, respectively (Table I).

Antioxidant power of powdered extract. Based on the neutralization of free DPPH towards its reduced form (DPPH-H), the antioxidant power of the eight different algae extracts was assessed by two methods. The first procedure compared the RSA of a fixed concentration of each extract $(1.0 \mathrm{mg} / \mathrm{ml})$ with that of ascorbic acid (also $1.0 \mathrm{mg} / \mathrm{ml}$ ). Expressed as a percentage (relative to the appropriate control), RSA was $>90 \%$ with ascorbic acid (96.1\%), the aqueous extract (94.2\%), the methanolic extract (94.1\%) and the hydromethanolic extract $(90.5 \%)$. RSA decreased to $82.6 \%$ with the ethanolic extract, $62.7 \%$ with the hydroethanolic extract, $46.7 \%$ with the petroleum ether extract, $42.3 \%$ with the butanolic extract and $39.9 \%$ with the acetone extract. There was a significant positive correlation between the ranking of these data (1-8) and the corresponding ranking for the total polyphenic content of the same eight extracts $(r=0.952 ; \mathrm{P}<0.001)$. Incidentally, the synthetic antioxidant BHT also demonstrated potent antioxidant power in this experimental procedure.

In the second procedure, the concentration-response association for the antioxidant effect was established in the $20-1,000 \mu \mathrm{g} / \mathrm{ml}$ range of ascorbic acid and the four most powerful algae extracts, (the aqueous, methanolic, ethanolic and hydromethanolic extracts) identified in the first experimental procedure. $\mathrm{The} \mathrm{IC}_{50}$ (the extract concentration providing $50 \%$ of radical scavenging activity) values were calculated from the plotted graph (Fig. 1) of scavenging activity against the concentration of the samples, by linear regression analysis. $\mathrm{IC}_{50}$ was $3.7 \mu \mathrm{g} / \mathrm{ml}$ for ascorbic acid, $5.1 \mu \mathrm{g} / \mathrm{ml}$ for the aqueous extract, $15.0 \mu \mathrm{g} / \mathrm{ml}$ for the methanolic extract, $52.9 \mu \mathrm{g} / \mathrm{ml}$ for the ethanolic extract and close to $160 \mu \mathrm{g} / \mathrm{ml}$ for the hydromethanolic extract. When comparing the ranking (1-5) of the latter results to those identified with the five same materials in the first experimental procedure used to assess their antioxidant power, the coefficient of correlation between the two distinct rankings amounted to $0.9(\mathrm{P}<0.05)$.

Ferric ion reducing power. The FRAP of ascorbic acid and the four most powerful algae extracts was examined following $4 \mathrm{~min}$ incubation in the presence of $1.0 \mathrm{mg} / \mathrm{ml}$ antioxidant agents. Expressing the experimental data in FRAP units (i.e. $\mathrm{mMFe}^{\mathrm{II}}$ per mg dry matter), the results were 1.83 for ascorbic 
Table I. Percentage of saturated and unsaturated fatty acids in the lipids of Asparagopsis taxiformis alga powder extract.

\begin{tabular}{lr}
\hline Fatty acid & $\%$ \\
\hline Saturated fatty acids & $23.17 \pm 0.11$ \\
C8:0 (octanoate) & $0.25 \pm 0.01$ \\
C10:0 (decanoate) & $0.01 \pm 0.00$ \\
C12:0 (dodecanoate) & $2.31 \pm 0.01$ \\
C13:0 (tridecanoate) & $3.20 \pm 0.01$ \\
C14:0 (tetradecanoate) & $3.77 \pm 0.05$ \\
C15:0 (pentadecanoate) & $6.52 \pm 0.04$ \\
C16:0 (hexadecanoate) & $3.73 \pm 0.03$ \\
C17:0 (heptadecanoate) & $1.25 \pm 0.03$ \\
C18:0 (octadecanoate) & $1.18 \pm 0.02$ \\
C20:0 (eicosanoate) & $0.94 \pm 0.03$ \\
Unsaturated fatty acids & $67.8 \pm 0.41$ \\
C15:1 (pentadecenoate) & $9.06 \pm 0.05$ \\
C16:1 (hexadecenoate) & $3.80 \pm 0.03$ \\
C17:1 (heptadecenoate) & $0.36 \pm 0.02$ \\
C18:1 (octadecenoate) & $3.52 \pm 0.02$ \\
C18:2 (octadecadienoate) & $7.75 \pm 0.07$ \\
C18:3 (octadecatrienoate) & $3.66 \pm 0.08$ \\
C20:3 (eicosatrienoate) & $1.38 \pm 0.07$ \\
C20:4 (eicosatetraenoate) & $1.19 \pm 0.03$ \\
C20:5 (eicosapentaenoate) & $1.60 \pm 0.04$ \\
C22:1 (docosadecenoate) & $2.78 \pm 0.05$ \\
C22:6 (docosahexaenoate) & \\
\hline & \\
\hline &
\end{tabular}

Data are presented as mean \pm standard error of the mean.

acid, 1.58 with the aqueous extract, 1.45 with the methanolic extract, 1.04 with the hydromethanolic extract and 0.90 with the ethanolic extract. These results yielded a ranking (1-5) identical to that reached when the antioxidant power of the same five compounds tested at the same concentration $(1.0 \mathrm{mg} / \mathrm{ml})$ was assessed by the DPPH procedure.

Trapping of nitric oxide radicals. Nitric oxide scavenging activity, expressed as a percentage, was $53.9 \%$ with ascorbic acid, $51.1 \%$ with the algae aqueous extract, $45.5 \%$ with the methanolic extract, $30.7 \%$ with the hydromethanolic extract, $27.2 \%$ with the ethanolic extract, $21.6 \%$ with the hydroethanolic extract, $17.1 \%$ with the butanolic extract, $16.7 \%$ with the acetone extract and $8.7 \%$ with the petroleum ether extract. The ranking of these results (1-9), compared with that obtained with the same material and at the same concentration $(1.0 \mathrm{mg} / \mathrm{ml})$ in the first procedure used to assess by the DPPH method the antioxidant power, yielded a positive correlation of $0.95(\mathrm{P}<0.001)$.

Inhibition of superoxide radical. The inhibition of the superoxide radical, expressed as a percentage, was $71.7 \%$ with ascorbic acid, $68.3 \%$ with the aqueous extract, $59.8 \%$ with the methanolic extract, $49.8 \%$ with the hydromethanolic extract, $40.8 \%$ with the ethanolic extract and $36.2 \%$ with the

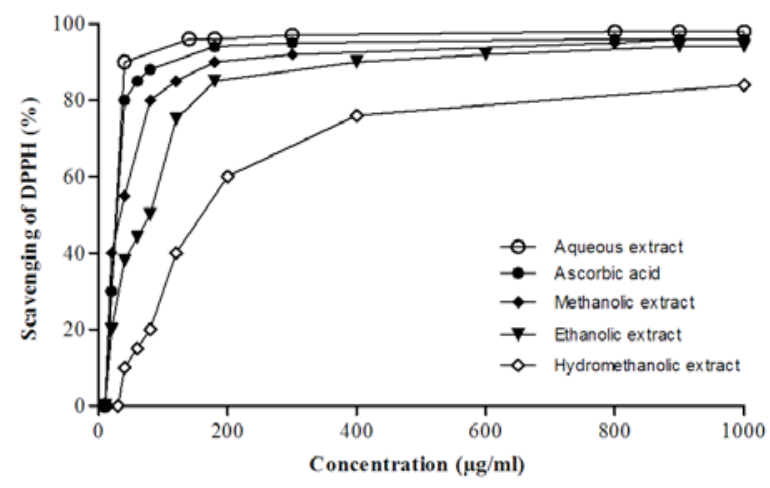

Figure 1. DPPH radical scavenging activities plotted against concentration of Asparagopsis taxiformis extracts (10-1,000 $\mu \mathrm{g} / \mathrm{ml})$. Aqueous extract (closed circles), methanolic extract (closed rhombus), ethanolic extract (closed triangles), hydromethanolic extract (open rhombus) and control; ascorbic acid (open circles) and expressed as the oxidation index $\mathrm{IC}_{50}\left(\mu \mathrm{g} . \mathrm{ml}^{-}{ }^{1}\right.$, mean \pm standard error of the mean, $n=3$ ) which was calculated from the graph by linear regression analysis. DPPH, 1,1-diphenyl-2-picryl-hydrazyl radical; $\mathrm{IC}_{50}$, half maximal inhibitory concentration.

hydroethanolic extract. The ranking of these data (1-6) was identical to that of the same six materials in the first experimental design used to assess their antioxidant power by the DPPH procedure. Incidentally, the synthetic antioxidant BHT yielded $81.2 \%$ inhibition in the same inhibition test of superoxide radical.

Inhibition of linoleic acid peroxidation. The inhibition of linoleic acid peroxidation by BHT and 4 algae extracts was examined in a concentration-related manner between 10 and $1,000 \mu \mathrm{g} / \mathrm{ml}$ of each tested agent (Fig. 2). At a mean concentration of $\sim 300 \mu \mathrm{g} / \mathrm{ml}$, the antioxidant activity, expressed as a percentage and derived from triplicate measurements, amounted to $80.1 \%$ with BHT, $70.1 \%$ with the aqueous extract, $62.8 \%$ with the methanolic extract, $49.2 \%$ with the hydromethanolic extract and $43.0 \%$ with the ethanolic extract. The ranking of these results (1-5) was identical to that for the same five matters in the superoxide radical inhibition test. Even the absolute values for the inhibition of linoleic acid peroxidation were virtually identical to those identified with the same five agents in the superoxide radical inhibitory procedure, the former absolute values averaging $102.5 \pm 1.5 \%(n=5 ; P>0.2)$ of the latter absolute values.

\section{Discussion}

Reactive oxygen species, such as the superoxide radical $\left(\mathrm{O}_{2}{ }^{-}\right)$, the hydroxyl radical $(\mathrm{OH})$, the peroxide radical $(\mathrm{RO})$ and the nitric oxide radical (NO), may attack biological molecules including lipids, proteins, enzymes, DNA or RNA and by doing so, provoke tissue lesions resulting in ageing, atherosclerosis and carcinogenesis (37-40).

Antioxidants are effective at protecting the body against damage caused by reactive oxygen species. There is increasing interest in developing treatments based on natural antioxidants, due to health problems and the toxicity of synthetic antioxidant lipids such as butylhydroxyanisol and BHT, which are often used in treatments (41-43). A number of natural 


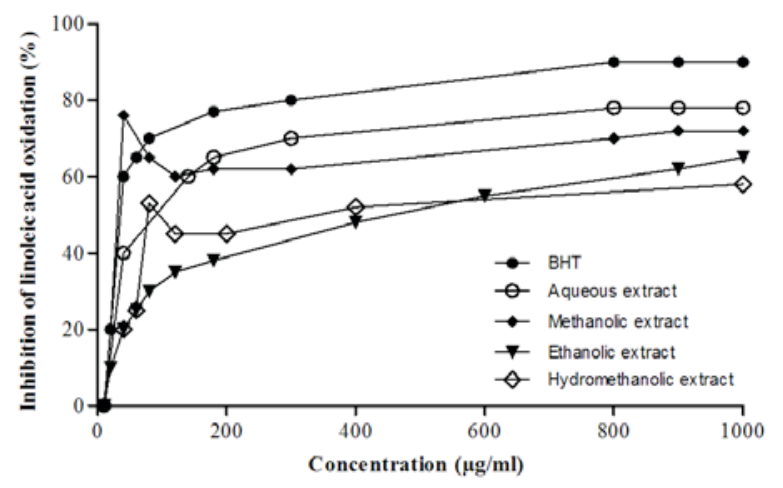

Figure 2. Inhibition of linoleic acid oxidation by BHT (closed circles) and marine algae (10-1,000 $\mu \mathrm{g} / \mathrm{ml})$ treated with aqueous extract (open circles), methanolic extract (closed rhombus), ethanolic extract (closed triangles) and hydromethanolic extract (open rhombus). BHT, butylated hydroxyltoluene.

antioxidants have already been isolated from oleaginous plants including grains, cereals, vegetables, leaves, roots, spices and herbs $(44,45)$. Among natural antioxidants, the most important are the phenolic compounds, which are generally found in plants.

Plants contain various phenolic compounds, including phenolic acids, anthocyanins, derivates of hydrocinnanic acids and flavonoids, as well as other simple phenolic compounds. All phenolic classes have structural characteristics classifying them as free radical scavengers and possess remarkable antioxidant potential. They are currently largely used as nutritional supplements (46-48). Natural antioxidants however, are not only found in ground plants. Certain algae species are also considered to be a rich source of antioxidants (49). A number of studies have demonstrated that chlorophyll, carotenoid and tocopherol derivatives, such as vitamin $\mathrm{E}$ and isoprenoids, extracted from sea algae are efficient antioxidants. They can be exogenously supplied to the cells, re-establishing the levels of oxidative and nitrogen stress by neutralizing the excess of free radicals and reactive species (50-53). The antioxidant effect of natural phenolic compounds has already been investigated regarding the prevention of coronary diseases, cancer and neurodegenerative diseases, including Alzheimer's, Parkinson's and amyotrophic lateral sclerosis (54-57). Furthermore, species of red algae from the rhodomelaceae family, particularly Asparagopsis taxiformis, are known for their richness in phenolic compounds, specifically bromophenols $(58,59)$.

These red Algae produce a variety of chemically active metabolites, including alkaloids, polyketides, cyclic peptides, polysaccharides, phlorotannins, diterpenoids, sterols, quinines, unsaturated lipids and glycerols which exhibit a large spectrum of diverse biological activities (60). A number of these metabolites, including iodine, caroten, glycerol, alginates and carraghenans, are currently used in the pharmaceutical industry to treat and manage oxidative stress-related human diseases. These include cancer, diabetes, inflammation, allergies and numerous bacterial, parasitic and fungal infections $(61,62)$.

Considering the results of the present study concerning extraction efficiency, it should be noted that previous studies have demonstrated that the chemical composition and extraction efficiency may vary due to the conditions and method followed, the algae parts used, the solvents and reagents used during extraction, the environment, algae genotype, its geographic origin and the harvesting period, in addition to the extent, condition, temperature and duration of the drying procedure $(63,64)$.

The Folin-Ciocalteu method used to measure total polyphenols is considered, in this perspective, as the best method due to its standardization, simplicity, reproducibility and restricted matrix interference (65).

A previous study characterizing the content of total phenolic compounds in two species of red sea algae (Porphyra tenera and Palmata palmata) demonstrated that the aqueous extracts of these two algae types contained high amounts of total polyphenols with 31.8 and $18.2 \mathrm{mg} . \mathrm{g}^{-1}$ gallic acid equivalent, compared respectively with 26.5 and $15.0 \mathrm{mg} \cdot \mathrm{g}^{-1}$ total polyphenols in methanolic extracts (66). Similarly, López et al (48) reported that aqueous extraction yielded an improved antioxidant capacity and elevated content of phenolic compounds, in accordance with the results of the present study.

Differences in the polyphenol total content among aqueous, methanolic and ethanolic extracts may be due to the relative solubility of such compounds in these extracts. The solubility of polyphenols depends on the type of solvent used, their polymerization degree, their interaction with other constituants and the formation of insoluble complexes. The high capacity of gross methanol to extract phenolic compounds has been previously documented (67). By contrast, there is much divergence concerning the efficiency of aqueous extraction, which remains dependent on the polarity of solubilized compounds. For example, only those compounds with high polarity are soluble in water and yield a high concentration of total phenolic compounds in aqueous extracts $(68,69)$.

It is therefore difficult to compare the present results with those of previous studies, as the use of different extraction methods in different studies does not allow results to be compared effectively. A number of factors may affect the concentration of phenolic compounds. Previous studies demonstrated that intrinsic factors such as geographic, climatic and genetic factors, in addition to the maturation extent of algae and the duration of their storage after collection, may influence polyphenol content (70). The present results support the possible role of multiple nutritional factors, specifically those linked to the simultaneous presence in algae of various compounds (fibers, minerals and proteins). The presence of metabolites in algae has prompted a pharmacological interest in their antioxidant, anti-radical, anticoagulant, antibacterial, antidiabetic, antifungal, anti-inflammatory, antiplatelet, antithrombic and vasodilatory properties, which may act on the cardiovascular, immunitary and nervous systems $(71,72)$.

The analysis of the fatty acid profile of Asparagopsis taxiformis in the current study revealed that pentadecanoic acid and docosahexaenoic acid were the most abundant saturated and unsaturated fatty acids, respectively. These findings differ from those reported by Gosch et al (73) who observed a high level of C22:6 (docosahexaenoate) in green algae but not in red algae. Khairy and El-Shafy (74), however, indicated that docosahexaenoic acid predominated in a number of different macro-algae. Belarbi et al (75) and 
Christi (76) indicated that algae oils differ from vegetable oils due to their richness in polyunsaturated fatty acids with $\geq 4$ double bounds, such as docosahexaenoic acid, which is abundant in algae oils.

Ragonese et al (77) conducted a study in two species of green sea algae (chloropyceae), two species of red sea algae (pheophyceae) and four species of brown sea algae (pheophyceae) collected in spring 2011 on the Sicilian coast of Messine Detroit (Italy). Relative to the total amount of the methylic esters of fatty acids, the saturated fatty acids represented 22.1, 41.7 and 52.5\%, respectively, in Dyctiota dicotoma, Pterocladiella capillacea and Asparagopsis taxiformis. Expressed in the same manner, palmitic acid (13.8 and 49.0\%) and myristic acid (4.5 to $18.2 \%)$, i.e. hexadecanoic (C16:0) and tetradecenic (C14:0) acid were, according to these authors, the most abundant saturated fatty acids in these algae (77). These percentages are about three times higher than those observed in other aquatic plants. In the same algae, only a trace amount of pentadecanoic acids were identified (3.7\%). Among monodesaturated fatty acids, octadecenoic acid (C16:1) and hexadecenoic acid (C16:1) were the most abundant, specifically in red algae, amounting to $20.6 \%$ for oleic acid and $2.9-11.7 \%$ for palmitic acid, as a percentage of total fatty acid methyl esters. The concentration of erucic acid (C22:169) did not exceed $0.2-1.1 \%$ in most tested algae including Enteromorpha intestinalis, Asparagopsis taxiformis and Dyctiota dicotoma, whilst Asparagopsis taxiformis contained $22-46 \%$ polyunsaturated fatty acids, primarily eicosapente-

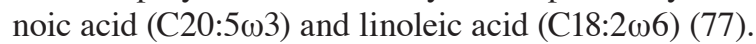

Variability in the fatty acid profile is dependent on the period of algae collection and, therefore, the temperature, $\mathrm{pH}$ and salinity (78). Variations may also reflect genetic diversity and changes in environmental parameters over different seasons with coinciding seasonable modifications in growth and abundance.

Antiradical activity is very important due to the deleterious role of free radicals in the alimentary domain and in biological systems. The DPPH method used in the present study is a typical procedure in which the antioxidant activity of the sample under consideration is estimated by the decolorization degree of the DPPH solution, the reduction of the latter radical resulting in its passage from violet to yellow in colour (79). The DPPH procedure may be adapted to a number of samples and its sensitivity allows the detection of very low concentrations, thus justifying its use in the estimation of antiradical activity in vegetable extracts (80).

Considering the present results, it is important to note that a number of factors, including the reaction conditions (time, type of solvents and their concentration, medium $\mathrm{pH}$ ) and profile of phenolic compounds, may affect the antioxidant potential and the reduction kinetics $(81,82)$. The chemical structure and antioxidant polarity determine the capacity to scavenge free radicals. Both synergic and antagonist effects were observed in model solutions containing numerous functional compounds with antiradical activity (83).

Phenolic compounds appear to be good candidates for antioxidant activity, considering the presence of numerous hydroxyls, which interact with free radicals (84). By contrast, numerous studies investigating different algae species have documented that antioxidant activity is not necessarily correlated with the content of phenolic compounds in the algae extracts, suggesting the presence of other substances such as pigments (chlorophyll and carotenoids) and sulfated polysaccharides of low molecular weight $(85,86)$. Furthermore, it was demonstrated that, due to their polarity, solvents may extract different compounds including pigments, alkaloids and phenolic compounds, in addition to essential oils rich in polyunsaturated fatty acids (87).

It has been suggested that phenolic compounds and bioactive phytochemical compounds (chlorophyll, carotenoids, sulfated polysaccharides, essential oils) present in algae extracts contribute to their radical scavenging capacity (88). The FRAP assay determines antioxidant activity by measuring the capacity of antioxidant compounds present in algae extracts to reduce ferric (III) to ferrous (II) iron in a colorimetric oxidation-reduction reaction based on electron transfer (89). The different reduced compounds present in the solution favour the reduction of the $\mathrm{Fe}^{3+} /$ ferrocyamide to its ferrous form $\left(\mathrm{Fe}^{2+}\right)$, which may be measured by absorbance at $700 \mathrm{~nm}$. The antioxidant activity relative to iron reduction is proportional to the optical density.

The results of the current study agree with those of a prior study (90) in which a weak reducing power, comparable in distinct extracts of red alga (Floridophyceae: Rhodophyta), was recorded at a concentration similar to that used in the present study $(1.0 \mathrm{mg} / \mathrm{ml})$. This suggests that phenolic compounds only serve a role in the scavenging of metallic ions and cannot represent the principal reducing agents of ferric ions $(91,92)$. Furthermore, the reducing power of the different extracts assessed is potentially due to the presence in phenolic compounds of hydroxyl groups that may act as electron donors. Thus, antioxidants are considered as reductants and inactivators of oxidants $(93,94)$.

The trapping of nitric oxide radicals was estimated by use of the Griess reaction, according to which, sodium nitroprusside produces NO in an aqueous solution at physiological $\mathrm{pH}$ 7.2. Under aerobic conditions, NO reacts with oxygen to generate nitrate and nitrite. The principle of this technique rests on the measurement of the capacity of tested extracts to trap nitric oxide, leading to a decreased production of nitrite ions (33).

The nitric oxide species or reactive nitrogen formed during the reaction with oxygen or superoxides, are responsible of the modification in the structural or functional behaviour of numerous cell components. The present study demonstrates that incubation of sodium nitroprusside in a saline phosphate buffer at $30^{\circ} \mathrm{C}$ for $2 \mathrm{~h}$ provokes a linear production of nitrites, which are reduced by the tested extracts of Asparagopsis taxiformis.

The potent antiradicular activity of the aqueous and methanolic extracts of the latter alga clearly documents the affinity of antioxidants, such as flavonoids or phenolic compounds, present in these extracts, which efficiently compete with oxygen to interact with nitric oxide and therefore, inhibit nitrite production $(95,96)$. Results from previous studies are in accordance with the preliminary results of the present study, which document an important antioxidant power of these extracts in terms of their capacity to scavenge the DPPH radical and reduce ferric $\mathrm{Fe}^{3+}$ ions to $\mathrm{Fe}^{2+}$.

The phenolic compounds appear to be good candidates for antioxidant activity due to the presence of numerous 
hydroxyls able to react with free radicals (97-99). Numerous studies (100-102) have established an association between the chemical structure of flavonoids and their antioxidant capacity. The trapping of free radicals by these molecules is associated with their structure: The most active flavonoids are those which contain $3^{\prime}-4$ ' dihydroxy groups on the B cycle and/or a $3-\mathrm{OH}$ group on the $\mathrm{C}$ cycle (103).

Superoxide radicals are produced endogenously by flavo-enzymes such as xanthine oxidase, which converts hypoxanthine to xanthine and then to uric acid in the process of ischemia-reperfusion. The measurement of the anion superoxide scavenging activity of the different Asparagopsis taxiformis extracts was based on the method proposed by Parejo et al (34). Superoxide radicals were generated by the oxidation of nicotinamide adenine dinucleotide (NADH) at the intervention of the hypoxanthine/xanthine oxidase and measured by the reduction of $\mathrm{NBT}^{2+}$ (Nitro-Blue-Tetrazolium). Thus, the anionic radical derived from molecular oxygen reduces the $\mathrm{NBT}^{2+}$ of yellow colour into the blue formazan of purple colour. The decrease in absorbance at $560 \mathrm{~nm}$ with the assessed extracts and the BHT and ascorbic acid antioxidants indicated the degradation of the superoxide radical in the reagent mixture.

The relative inhibition of superoxide radical generation yielded with the positive standards and the various algae extracts results are comparable, in terms of the corresponding efficiency ranking, to those recorded with the DPPH procedure, the FRAP and the trapping of nitric oxide radicals. The superoxide radical is a noxious element inducing damage in cell components and represents the principle precursor of the most potent reactive oxygen species.

A number of studies have investigated the antioxidant properties of flavonoids in terms of anionic superoxide scavenging $(104,105)$. The antioxidant potential of Asparagopsis taxiformis extracts indicates that algae extracts exert cytoprotective effects and supports their use as to treat conditions induced by oxidant stress.

In the present study, the antioxidant activity of Asparagopsis taxiformis extract was also assessed by inhibition of linoleic acid oxidation, using the ferric thiocyanate method, according to the procedure described by Bidie et al (35). The peroxidation of linoleic acid leads to the oxidation of $\mathrm{Fe}^{2+}$ to $\mathrm{Fe}^{3+}$. The latter ion forms a complex with the thiocyanate, the absorbance of which is read at $500 \mathrm{~nm}$. Thus, the increase in absorbance is proportional to the amount of peroxides formed during incubation of the emulsion. The results of the current study demonstrate the capacity of polar compounds present in Asparagopsis taxiformis to inhibit linoleic acid peroxidation and decrease the formation of hydroperoxides, indicating that this alga represents a source of natural antioxidants.

It should be stressed that Algeria, with its $>1,600 \mathrm{~km}$ long Mediterranean front, represents a country with good access to the sea. Thus, relative to other countries, it potentially has easy access to very important algae biomass.

The valorization of this algae biomass has to be taken into consideration in the national plans concerning the exploitation of Algerian coastline and waters. Algae already have a recognized commercial value in various fields. They are an important source of polysaccharides used as emulsifying, thickening and stabilizing agents in the food industry. Their antibiotic, antiviral and anti-inflammatory properties confer on them additional pharmaceutical and medical value. Furthermore, considering the other potential properties of these substances, numerous industries are interested in developing novel products and applications derived from them.

In conclusion, taking into account the antioxidant power of these natural substances, they may potentially offer notable applications. Further studies are required to identify and isolate bioactive molecules crude algae extracts and to comprehensively evaluate the biological in vivo activities of each isolated compound.

The present study revealed that extracts from Asparagopsis taxiformis exhibit antioxidant activity. This antioxidant activity was most pronounced in the aqueous and methanolic extracts. This marine algae species may therefore be a valuable source of antioxidant agents and an alternative to synthetic ingredients in pharmaceuticals and food manufacturing. Aspargopsis taxiformis may have therapeutic value in the treatment and/or prevention of oxidative stress-related diseases.

\section{References}

1. Chatter Riahi R, Tarhouni S and Kharrat R: Screening of anti-inflammatory and analgesic activities in marines macroalgae from Mediterranean Sea 88: 19-28, 2011 (In French).

2. Kong CS, Kim JA, Yoon NY and Kim SK: Induction of apoptosis by phloroglucinol derivative from Ecklonia cava in MCF-7 human breast cancer cells. Food Chem Toxicol 47: 1653-1658, 2009 .

3. Nwosu F, Morris J, Lund VA, Stewart D, Ross HA and McDougall GJ: Anti-proliferative and potential anti-diabetic effects of phenolic-rich extracts from edible marine algae. Food Chem 126: 1006-1012, 2011.

4. Pangestuti R and Kim SE: Neuroprotective effects of Marine Algae. Mar Drugs 9: 803-818, 2011.

5. Mahesha M, Poojary J, Vishnumurthy KA and Adhikari AV: Extraction, characterization and biological studies of phytochemicals from Mammea suriga. J Pharm Anal 5: 182-189, 2015.

6. Spolaore P, Joannis-Cassan C, Duran E and Isambert A: Commercial applications of macroalgae. J Biosci Bioeng 101: 87-96, 2006.

7. El Gamal AA: Biological importance of marine algae. Saudi Pharm J 18: 1-25, 2010

8. Jassbi AR, Mohabati M, Eslami S, Sohrabipour J and Miri R: Biological activity and chemical constituents of red and brown algae from the persian gulf. Iran J Pharm Res 12: 339-348, 2013

9. Frenz JL, Kohl AC and Kerr RG: Marine natural products as therapeutic agents: Part 2. Expert Opin Ther Pat 14: 17-33, 2004

10. Mišurcová L: Chemical composition of seaweeds. In: Handbook of Marine Macroalgae. Biotechnology and Applied Phycology. Chichester, UK, pp173-192, 2011.

11. Ambrozova JV, Misurcova L, Vicha R, Machu L, Samek D, Baron M, Mlcek J, Sochor J and Jurikova T: Influence of extractive solvents on lipid and fatty acids content of edible freshwater algal and seaweed products. the green microalga Chlorella kessleri and the cyanobacterium Spirulina platensis. Molecules 19: 2344-2360, 2014.

12. El-baroty GS, Moussa MY, Shallan MA, Ali MA, Sabh AZ and Shalaby EA: Contribution to the Aroma, biological activities, minerals, protein, pigments and lipid contents of the red Alga: Asparagopsis taxiformis (Delile) Trevisan. J appl Sci Res 3: 1825-1834, 2007.

13. Genovese G, Tedone L, Hamann MT and Morabito M: The mediterranean red alga asparagopsis: A source of compounds against leishmania. Mar Drugs 7: 361-366, 2009.

14. Bouhlal R, Haslin C, Chermann JC, Colliec-Jouault S, Sinquin C, Simon G, Cerantola S, Riadi H and Bourgougnon N: Antiviral activities of sulfated polysaccharides isolated from Sphaerococcus coronopifolius (Rhodophytha, Gigartinales) and Boergeseniella thuyoides (Rhodophyta, Ceramiales). Mar Drugs 9: 1187-1209, 2011. 
15. Plaza M, Cifuentes A and Ibáñez E: In the search of new functional food ingredients from algae. Trends in Food Science \& Technology 19: 31-39, 2008.

16. Vadalà M and Palmieri B: From algae to 'functional foods'. Clin Ter 166: 281-300, 2015 (In Italian).

17. Kohen R and Nyska A: Oxidation of biological systems: Oxidative stress phenomena, Antioxidants, redox reactions, and methods for their quantification. Toxicolo Pathol 30: 620-650, 2002.

18. Heo SJ, Park PJ, Park EJ, Kim SK and Jeon YJ: Antioxidant activity of enzymatic extracts from a brown seaweed Ecklonia cava by electron spin resonance spectrometry and comet assay. Eur Food Res Technol 221: 41-47, 2005.

19. Mayer AM and Gustafson KR: Marine pharmacology in 2003-2004: Anti-tumour and cytotoxic compounds. Eur J Cancer 42: 2241-2270, 2006.

20. Murugan K and Iyer VV: Antioxidant and Antiproliferative Activities of Marine Algae: Gracilaria edulis and Enteromorpha lingulata, from Chennai Coast. Int J Cancer Res 8: 15-26, 2012

21. Kim S and Wijesekara I: Development and biological activities of marine-derived bioactive peptides: A review. J Funct Foods: 2: $1-9,2010$

22. Chernane H, Mounir M, Latique S and El kaoua: Evaluation of antioxidant capacity of methanol extract and its solvent fractions obtained from four maroccan macro algae species. Eur Sci J Edition 10: 10-15, 2014.

23. Sanchez-Roman I and Barja G: Regulation of longevity and oxidative stress by nutritional interventions: Role of methionine restriction. Exp Gerontol 48: 1030-1042, 2013.

24. Li H, Horke S and Förstermann U: Vascular oxidative stress, nitric oxide and atherosclerosis. Atherosclerosis 237: 208-219, 2014

25. Singleton VL, Orthofer R and Lamuela-Raventós RM: Analysis of total phenols and other oxidation substrates and antioxidant by means of Folin-Ciocalteu reagent. Methods Enzymol 299: 152-178, 1999.

26. Lugue de Castro MD and Garcia-Ayuso LE: Soxhlet extraction of solid materials: An outdated technique with a promising innovative future. Annal Chim Acta 369: 1-10, 1998.

27. Bligh EG and Dyer WJ: A rapid method of total lipid extraction and purification. Can J Biochem Physiol 37: 911-917, 1959.

28. Christie WW: Gas chromatography-mass spectrometry methods for structural analysis of fatty acids. Lipids 33: 343-353, 1998

29. Carvalho MS, Mendonça MA, Pinho DM, Resck IS and Suarez AZ: Chromatographic analyses of fatty acid methyl esters by HPLC-UV and GC-FID. J Braz Chem Soc 23: 763-769, 2012.

30. Cristina P, Ilonka S and et Bartosz T: Evaluation of the antioxidant activity of the phenolic compounds by reactivity with the free radical. Ind Eng Journal 4: 25-39, 2009.

31. Benzie IF and Strain JJ: The ferric reducing ability of plasma (FRAP) as a measure of 'antioxidant power': The FRAP assay. Anal Biochem 239: 70-76, 1996.

32. Green LC, Wagner DA, Glogowski J, Skipper PL, Wishnok JS and Tannenbaum SR: Analysis of nitrate, nitrite, and $[15 \mathrm{~N}]$ nitrate in biological fluids. Anal Biochem 126: 131-138, 1982

33. Singh D, Mishra M, Gupta M, Singh P, Gupta A and Nema R Nitric Oxide radical scavenging assay of bioactive compounds present in methanol Extract of Centella asiatica. Int J Pharm Pharm Sci Res 2: 42-44, 2012.

34. Parejo I, Viladomat F, Bastida J, Rosas-Romero A, Flerlage N, Burillo J and Codina C: Comparison between the radical scavenging activity and antioxidant activity of six distilled and non distilled Mediterranean herbs and aromatic plants. J Agric Food Chem 50: 6882-6890, 2002

35. Bidie AP, Bahi G, Meite S, Yapo AF, N'guessan JD and Djaman AJ: Evaluation of the antioxidant activity of tota aqueous extract of Bridelia ferruginea benth. (Euphorbiaceae). World J Pharm Sci 3: 2125-2134, 2015.

36. Snedecor GW and Cochran WG: Statistical methods applied to experiments in agriculture and biology. Iowa State University Press, 5th ed. pp183-189, 1956.

37. Valentão P, Fernandes E, Carvalho F, Andrade PB, Seabra RM and Bastos ML: Antioxidative properties of Cardoon (Cynara cardunculus L.) infusion against superoxide radical, hydroxyl radical, and hypochlorous acid. J Agric Food Chem 50: 4989-4993, 2002

38. Fisch KM, Böhm V, Wright AD and König GM: Antioxidative meroterpenoids from the brown alga Cystoseira crinite. J N Prod 66: 968-975, 2003
39. Nakamura Y, Watanabe S, Miyake N, Kohno H and Osawa T: Dihydrochalcones: Evaluation as novel radical scavenging antioxidants. J Agric Food Chem 51: 3309-3312, 2003.

40. Chandini SK, Ganesan P and Bhaskar N: In vitro antioxidant activities of three selected brown seaweeds of India. Food Chem 107: 707-713, 2008.

41. Howell JC: Food antioxidants: International perspectives-welcome and introductory remarks. Food Chem Toxicol 24: 997, 1986.

42. Ito N, Hirose M, Fukushima S, Tsuda H, Shirai $T$ and Tatematsu M: Studies on antioxidants: Their carcinogenic and modifying effects on chemical carcinogenesis. Food Chem Toxicol 24: 1071-1082, 1986

43. Amarowicz R, Naczk M and Shahidi F: Antioxidant activity of various fractions of non-tannin phenolics of Canola hulls. J Agric Food Chem 48: 2755-2759, 2000.

44. Wettasinghe M and Shahidi F: Antioxidant and free radical-scavenging properties of ethanolic extracts of defatted borage (Borago officinalis L.) seeds. Food Chem 67: 399-414, 1999.

45. Shon MY, Kim TH and Sung NJ: Antioxidants and free radical scavenging activity of Phellinus baumii (Phellinus of Hymenochaetaceae) extracts. Food Chem 82: 593-597, 2003

46. Bandoniene D and Murkovic M: On-line HPLC-DPPH screening method for evaluation of radical scavenging phenols extracted from apples (Malus domestica L.). J Agric Food Chem 50: 2482-2487, 2002.

47. Devi GK, Maniyannan K, Thirumaran G, Rajathi FA and Anantharaman P: In vitro antioxidant activities of selected seaweeds from Southeast coast of India. Asian Pac J Trop. Med 4: 205-211, 2011.

48. López A, Rico M, Rivero A and De Tangil MS: The effects of solvents on the phenolic contents and antioxidant activity of Stypocaulon scoparium (algae) extracts. Food Chem 125: 1104-1109, 2011.

49. Lim SN, Cheung PC, Ooi VE and Ang PO: Evaluation of antioxidative activity of extracts from a brown seaweed, Sargassum siliquastrum. J Agric Food Chem 50: 3862-3866, 2002.

50. Farombi EO, Britton G and Emerole GO: Evaluation of the antioxidant activity and partial characterisation of extracts from browned yam flour diet. Food Res Intern 33: 493-499, 2000.

51. Kaur C and Kapoor HC: Antioxidants in fruits and vegetables-the millennium's health. Int J Food Sci Technol 36: 703-725, 2001.

52. Takamatsu S, Hodges TW, Rajbhandari I, Gerwick WH, Hamann MT and Nagle DG: Marine natural products as novel antioxidant prototypes. J N Prod 66: 605-608, 2003.

53. Canadanovic-Brunet JM, Djilas SM, Cetkovic GS, Tumbas VT, Mandic AI and Canadanovic VM: Antioxidant activities of different Teucrium montanum L. extracts. Int J Food Sci Technol 41: 667-673, 2006

54. Stoclet JC, Chataigneau T, Ndiaye M, Oak MH, El Bedoui J, Chataigneau M and Schini-Kerth VB: Vascular protection by dietary polyphenols. Eur J Pharmacol 500: 299-313, 2004.

55. Cole GM, Lim GP, Yang F, Teter B, Begum A, Ma Q Harris-White ME and Frautschy SA: Prevention of Alzheimer's disease: Omega-3 fatty acid and phenolic anti-oxidant interventions. Neurobiol Aging 26 (Suppl 1): S133-S136, 2005.

56. Fraga CG: Plant polyphenols: How to translate their in vitro antioxidant actions to in vivo conditions. IUBMB Life 59: 308-315, 2007

57. Fusco D, Colloca G, Lo Monaco MR and Cesari M: Effects of antioxidant supplementation on the aging process. Clin Interv Aging 2: 377-387, 2007.

58. de Carvalho LR and Roque NF: Halogenated and/or sulfated phenols from marine macroalgae. Quimica Nova 23: 757-764, 2000.

59. Zhao J, Fan X, Wang S, Li S, Shang S, Yang Y, Xu N, Lü Y and Shi J: Bromophenol derivatives from the red alga Rhodomela confervoides. J Nat Prod 67: 1032-1035, 2004.

60. Al-Saif SS, Abdel-Raouf N, El-Wazanani HA and Aref IA Antibacterial substances from marine algae isolated from Jeddah coast of Red sea, Saudi Arabia. Saudi J Biol Sci 21: 57-64, 2014.

61. Kharkwal H, Joshi DD, Panthari P, Pant MK and Kharkwal AC: Algae as future drugs. Asian J Pharm Clin Res 5: 1-4, 2012.

62. Kolanjinathan K, Ganesh P and Saranraj P: Pharmacological importance of seaweeds. World J Fish Mar Sci 6: 01-15, 2014.

63. Bajpai VK and Rahman A and Kang SC: Chemical composition and inhibitory parameters of essential oil and extracts of Nandina domestica Thunb. To control food-borne pathogenic and spoilage bacteria. Int J Food Microbiol 125: 117-122, 2008. 
64. Kelen M and Tepe B: Chemical composition, antioxidant and antimicrobial properties of the essential oils of three Salvia species from Turkish flora. Bioresour Technol 99: 4096-4104, 2008.

65. Djeridane A, Yousfi M, Brunel JM and Stocker P: Isolation and characterization of a new steroid derivative as a powerful antioxidant from Cleome Arabica in screening the in vitro antioxidant capacity of 18 Algerian medicinal plants. Food Chem Toxicol 48: 2599-2606, 2010

66. Machu L, Misurcova L, Ambrozova JV, Orsavova J, Mlcek J, Sochor J and Jurikova T: Phenolic content and antioxidant capacity in algal food products. Molecules 20: 1118-1133, 2015.

67. Falleh H, Ksouri R, Chaieb K, Karray-Bouraoui N, Trabelsi N, Boulaaba $\mathrm{M}$ and Abdelly C: Phenolic composition of Cynara cardunculus L. Organs, and their biological activities. C R Biol 331: 372-379, 2008.

68. Hanaa H, El-Baky A, El Baz FK and El Baroty GS: Evaluation of Marine Alga Ulva Lactuca L. As a source of natural preservative ingredient. J Agric Envir Sci 3: 434-444, 2008.

69. Mounir M and Salma LI: Evaluation of antioxidant capacity of methanol extract and its solvent fractions obtained from four Moroccan macro algae species. Sci Europ J 10: 10-15, 2014.

70. Aganga AA and Mosase KW: Tannin content, nutritive value and dry matter digestibility of Lonchocarpus capassa, Zizyphus mucronata, Sclerocarya birrea, Kirkia acuminata and Rhus lancea seeds. Animal Feed Sci Technol 91: 107-113, 2001.

71. Gülçin I, Huyut Z, Elmastas M and Aboul-Enein HY: Radical scavenging and antioxidant activity of tannic acid. Arabian J Chem 3: 43-53, 2010

72. Taboada C, Millan R and Miguez I: Evaluation of marine algae Undaria pinnatifida and Porphyra purpurea as a food supplement: Composition, nutritional value and effect of intake on intestinal, hepatic and renal enzyme activities in rats. J Sci Food Agric 93: 1863-1868, 2013.

73. Gosch BJ, Magnusson M, Paul NA and De Nys R: Total lipid and fatty acid composition of seaweeds for the selection of species for oil-based biofuel and bioproducts. Bioenergy 4: 919-930, 2012.

74. Khairy HM and El-Shafay SM: Seasonal variations in the biochemical composition of some common seaweed species from the coast of Abu Qir Bay, Alexandria, Egypt. Oceanologia 55: 435-452, 2013.

75. Belarbi EH, Molina E and Chisti Y: A process for high yield and scaleable recovery of high purity eicosapentaenoic acid esters from microalgae and fish oil. Enzyme Microb Technol 26: 516-529, 2000.

76. Chisti Y: Biodiesel from microalgae. Biotechnol Adv 25: 294-306, 2007.

77. Ragonese C, Tedone L, Beccaria M, Torre G, Cichello F Cacciola F, Dugo P and Mondello L: Characterisation of lipid fraction of marine macroalgae by means of chromatography techniques coupled to mass spectrometry. Food Chem 145: 932-940, 2014.

78. Holton RW, Blicker HH and Onore M: Effect of growth temperature on the fatty acid composition of a blue-green algae. Phytochemistry 3: 595-602, 1964.

79. Gülçin I, Alici HA and Cesur M: Determination of in vitro antioxidant and radical scavenging activities of propofol. Chem Pharm Bull (Tokyo) 53: 281-285, 2005.

80. Yi Z, Yan Y, Liang Y and Zeng B: In vitro antioxidant and antimicrobial activities of Pericarpium Citri Reticulatae of a new Citrus Cultivar and its main flavonoids. LWT-Food Science and Technology 41: 597-603, 2008.

81. Sharma OP and Bhat TK: DPPH antioxidant assay revisited. Food Chem 113: 1201-1205, 2009.

82. Molyneux P: The use of stable free radical diphenylpicrilhydrazyl (DPPH) for estimating antioxidant activity. Songklanakarin J Sci Technol 26: 211-219, 2004.

83. Birben E, Sackesen C, Erzurum S and Kalayci O: Oxidative stress and antioxidant defense. World Allergy Organ J 5: 9-19, 2012.
84. Sokol-Letowska A, Oszmianski J and Wojdylo A: Antioxidant activity of the phenolic compound of hawthorn, pine and skullcap. Food Chem 103: 853-859, 2007.

85. Indriatmoko H, Limantara L and Panintingjati Brotosudarmo TH: Composition of Photosynthetic Pigments in A Red Alga Kappaphycus alvarezi Cultivated in Different Depths. Procedia Chemistry 14: 193-201, 2015.

86. Takaichi S: Carotenoids in Algae: Distributions, biosyntheses and functions. Mar Drugs 9: 1101-1118, 2011.

87. Abd El-Aty AM, Mohamed AA and Samhan FA: In vitro antioxidant and antibacterial activities of two fresh water Cyanobacterial species, Oscillatoria agardhii and Anabaena sphaerica. J App Pharm Sci 4: 69-75, 2014.

88. Kumar KS, Ganesan K and Subba Rao PV: Antioxidant potential of solvent extracts of Kappaphycus alvarezii (Doty) Doty-An edible seaweed. Food Chem 107: 289-295, 2008.

89. Chew YL, Lim YY, Omar M and Khoo KS: Antioxidant activity of three edible seaweeds from two areas in South East Asia. LWT Food Sci Technol 41: 1067-1072, 2008

90. Alencar B, Silva SR, Pires-Cavalcante KM, Lima RL, Pereira Júnior FN, Sousa MB, Viana FA, Nagano CS, Nascimento KS Cavada BS, et al: Antioxidant potential and cytotoxic activity of two red seaweed species, Amansia multifida and Meristiella echinocarpa, from the coast of Northeastern Brazil. An Acad Bras Cienc 86: 251-263, 2014.

91. Meenakshi S, Umayaparvathi S, Arumugam $M$ and Balasubramanian $\mathrm{T}$ : In vitro antioxidant properties and FTIR analysis of two seaweeds of Gulf of Mannar. Asian Pacific J Tropic Biomed 1: 66-70, 2011

92. Mounir M and Salma L: Evaluation of antioxidant capacity of methanol extract and its solvent fractions obtained from four Moroccan macro algae species. Sci Europ J 10: 10-15, 2014.

93. Siddhuraju P and Becker K: The antioxidant and free radical scavenging activities of processed cowpea (vigna unguiculata (L.) Walp.) seed extracts. Food Chem 101: 10-19, 2007.

94. Kumaran A and Karunakaran RJ: In vitro antioxidant activities of methanol extracts of five Phyllanthus species from India. Lebensmittel-Wissenschaft und Technologie 40: 344-352, 2007.

95. Crozier A, Del Rio D and Clifford MN: Bioavailability of dietary flavonoids and phenolic compounds. Mol Aspects Med 31: 446-467, 2010.

96. Jagetia GC, Rao SK, Baliga MS and Babu SK: The evaluation of nitric oxide scavenging activity of certain herbal formulations in vitro: A preliminary study. Phytother Res 18: 561-565, 2014.

97. Verzelloni E, Tagliazucchi D and Conte A: Relationship between the antioxidant properties and the phenolic and flavonoid content in traditional balsam vinegar. Food Chem 105: 564-571, 2007.

98. Sengul M, Yildiz H, Gungor N, Cetin B, Eser Z and Ercisli S: Total phenolic content, antioxidant and antimicrobial activities of some medicinal plants. Pak J Pharm Sci 22: 102-106, 2009.

99. Zhang L, Ravipati AS, Koyyalamudi SR, Jeong SC, Reddy N Smith PT, Bartlett J, Shanmugam K, Münch G and Wu MJ: Antioxidant and anti-inflammatory activities of selected medicinal plants containing phenolic and flavonoid compounds. J Agric Food Chem 59: 12361-12367, 2011.

100. Kumar S and Pandey AK: Chemistry and biological activities of flavonoids: An Overview. The Sci World J 2013: 162750, 2013.

101. Kozłowska A and Szostak-Wegierek D: Flavonoids-food sources and health benefits. Rocz Panstw Zakl Hig 65: 79-85, 2014.

102. Csepregi K, Neugart S, Schreiner M and Hideg É: Comparative evaluation of total antioxidant capacities of plant polyphenols. Molecules 21: pii: E208, 2016.

103. Chan PT, Matanjun P, Yasir SM and Tan TS: Antioxidant activities and polyphenolics of various solvent extracts of red seaweed. Gracilaria changii. J Appl Phycol 27: 2377-2386, 2015.

104. Fernando IP, Kim M, Son KT, Jeong Y and Jeon YJ: Antioxidant activity of marine algal polyphenolic Compounds: A mechanistic approach. J Med Food 19: 615-628, 2016.

105.Zeng LM, Wang CJ, Su JY, Li D, Owen NL, Lu Y, Lu N and Zheng QT: Flavonoids from the red alga Acanthophora spicifera. Chin J Chem 19: 1097-1100, 2001. 